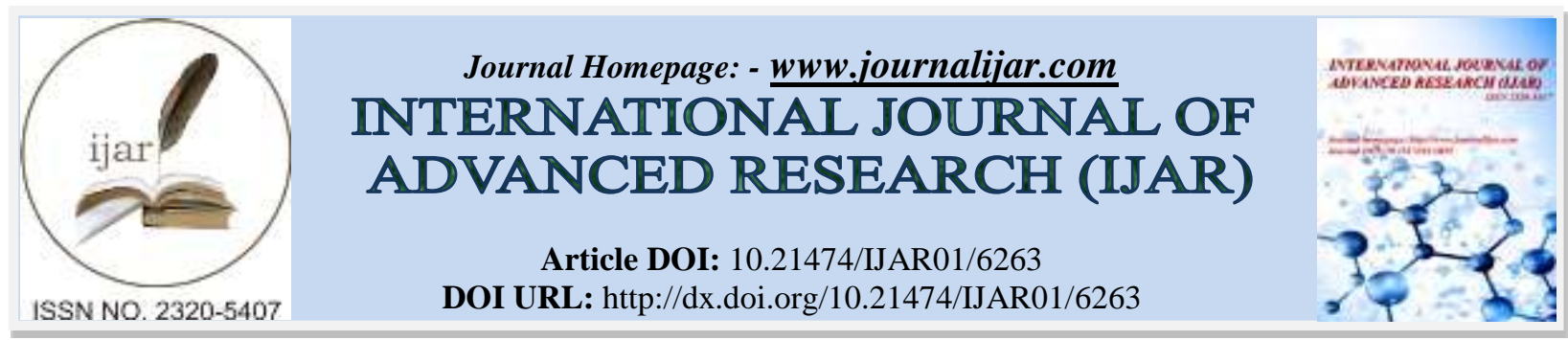

RESEARCH ARTICLE

\title{
A STUDY OF HEAD INJURY PATIENTS IN A TERTIARY CARE HOSPITAL OF TRIPURA, INDIA.
}

\section{Dr. Anup Kumar Saha ${ }^{1}$, Dr. Sunil Kumar Ghosh ${ }^{2}$, Dr. Kishan Rao B ${ }^{3}$ and Dr. Atanu Sengupta ${ }^{3}$.}

1. Professor and HOD, Department of General Surgery, Agartala Government Medical College and G.B.P. Hospital, Agartala 799006, Tripura, India.

2. Assistant Professor, Department of General Surgery, Agartala Government Medical College and G.B.P. Hospital, Agartala 799006, Tripura, India.

3. Post Graduate Resident, Department of General Surgery, Agartala Government Medical College and G.B.P. Hospital, Agartala 799006, Tripura, India.

\section{Manuscript Info}

Manuscript History

Received: 09 November 2017

Final Accepted: 11 December 2017

Published: January 2018

\section{Abstract}

Background: India has the rather unenviable distinction of having the highest rate of head injury in the world. In India, more than 100,000 lives are lost every year with over 1 million suffering from serious head injuries. In India, 1 out of 6 trauma victims die, while in the United States this figure is 1 out of 200. This seemingly unbreachable gap speaks volumes of the perfected trauma management procedures in US and their near absence in India. The global incidence rate of traumatic head injury is estimated at 200 per 100000 people per year; however, this rate is uncertain and a likely underestimate. Traumatic brain injury according to the World Health Organization, will surpass many diseases as the major cause of death and disability by the year 2020 . With an estimated 10 million people affected annually by traumatic head injury, the burden of mortality and morbidity that this condition imposes on society, makes traumatic head injury a pressing public health and medical problem.

Methods: Hospital based Cross Sectional study.

Results: Road Traffic Accident(RTA) was found to be the leading $(65.7 \%)$ cause of traumatic brain injury mostly in the age group of 2130 years of age. However, in case of age group 1-10 years, fall was found to be the most common factor. Injuries ranged from scalp hematoma (75\%) cases followed by cerebral contusions in $26.3 \%$.

Conclusion: Road Traffic Accidents (RTA) was the most common cause of head injury, with most common affected group being the young adult males. As much as $40 \%$ of these injuries were found to be in urgent need of medical attention.

Copy Right, IJAR, 2018,. All rights reserved.

\section{Introduction:-}

Head injury is one of the most devastating types of injury, and it results in varying degrees of paralysis, loss of consciousness, amnesia and even death. Head trauma accounts for the majority of trauma deaths [1]. The effects of serious head injury are not limited to an individual's health; it also creates a financial burden for families and societies. The burden of traumatic head injury is manifested throughout the world, and is especially prominent in 
Low and Middle-Income Countries which face a higher preponderance of risk factors for causes of traumatic head injury and have inadequately prepared health systems to address the associated health outcomes. Half of those who die from Traumatic brain injury do so within the first two hours of injury. It is now known that only a portion of neurological damage occurs at the moment of impact (primary injury); damage progresses during the ensuing minutes, hours and days. The secondary brain injury can result in increased mortality and disability.

Consequently, the early and appropriate management of head injury is critical to the survival of these patients. Thus Time, while being a critical factor in the overall prospects of a patient is yet to be fully appreciated. Research has also shown that traumatic brain injury (TBI) usually requires long-term care and therefore incurs economic cost to health systems. For this reason,India needs to develop surveillance systems and conduct epidemiologic studies to measure the impact of neurotrauma among their people to guide the development of more effective preventive methods

\section{Materials and methods:-}

Study Design: Hospital based Cross-sectional study.

Study Setting: Department of General Surgery, A.G.M.C \& G.B.P. Hospital.

Study population: All patients admitted in General surgery wards with Head injury.

Study duration: 1 year (October 2016 to September 2017)

Inclusion criteria: patients of all age and sex admitted with head injury in the general surgery ward of A.G.M.C \& G.B.P. Hospital

Exclusion criteria: 1) patients who do not give consent

2) brought dead cases

Sample size: all patients admitted in the duration of study period in the ward.

Study tools: The study participants were briefed regarding the purpose of the study and their consent was taken. Data was collected by interviewing the patient and using the clinical and diagnostic reports.

Ethical consideration: Ethical committee approval and informed consent was taken from every patient explaining the full study before being included in the study.

\section{Results:-}

Total of 1134 patients were included in the study out of which $815(71.86 \%)$ were male and $319(28.14 \%)$ were female. Among these, the age group of 21-30 years was the most common affected group, with 265 (23.36\%) males and $88(7.8 \%)$ females.

\begin{tabular}{|l|l|l|l|l|}
\hline SR.NO. & AGE & MALE & FEMALE & TOTAL \\
\hline 1 & $1-10$ & $68(6 \%)$ & $20(1.76 \%)$ & $88(7.76 \%)$ \\
\hline 2 & $11-20$ & $\begin{array}{l}92 \\
(8.11 \%)\end{array}$ & $22(1.8 \%)$ & $114(10 \%)$ \\
\hline 3 & $21-30$ & $\begin{array}{l}265 \\
(23.36 \%)\end{array}$ & $88(7.8 \%)$ & $353(31.2 \%)$ \\
\hline 4 & $31-40$ & $\begin{array}{l}155 \\
(13.66 \%)\end{array}$ & $70(6.17 \%)$ & $225(20 \%)$ \\
\hline 5 & $41-50$ & $\begin{array}{l}143 \\
(12.6 \%)\end{array}$ & $82(7.2 \%)$ & $225(20.4 \%)$ \\
\hline 6 & $51+$ & $\begin{array}{l}92 \\
(8.11 \%)\end{array}$ & $37(3.26 \%)$ & $129(11.4 \%)$ \\
\hline & & $\begin{array}{l}815 \\
(71.86 \%)\end{array}$ & $319(28.14 \%)$ & 1134 \\
\hline
\end{tabular}


Most common cause of head injury was found to be road traffic accidents (RTA) with 745 (65.7\%) recorded patients followed by fall $260(22.9 \%)$ cases and assaults in the remaining 129(11.34\%) patients.

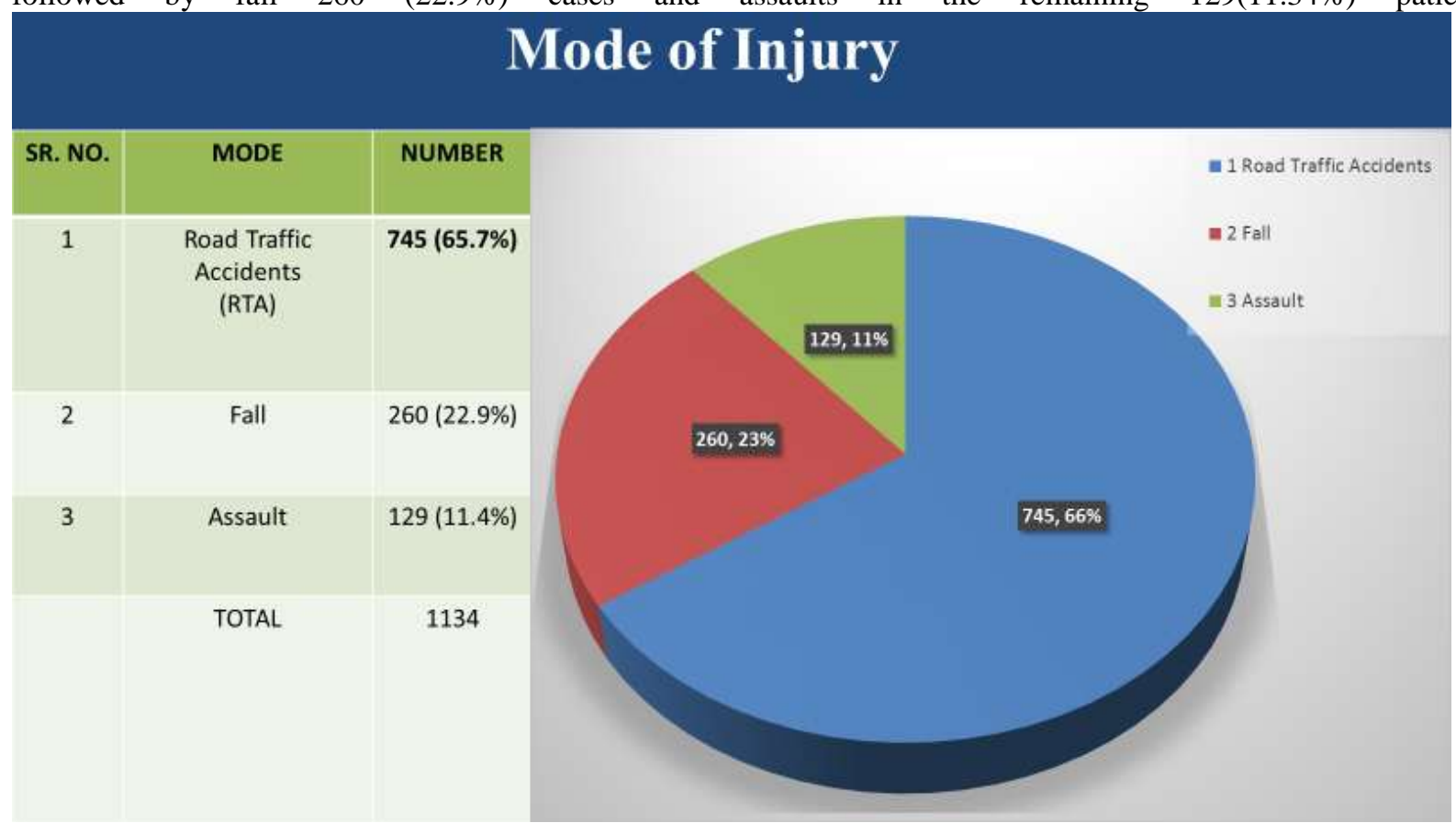

Road traffic accidents RTA was found to be most common in the age group of 21 - 30 years having $242(32.48 \%)$ patients included in the study with road traffic accident (RTA), while fall was most common in the age group of 010 years with $88(33.84 \%)$ of total patients admitted with history of fall, followed by assault being more common in the age group of $21-30$ years with 46 patients $(35.65 \%)$.

\section{Mode of Injury in different age groups}

\begin{tabular}{|c|c|c|c|c|c|c|c|}
\hline $\begin{array}{l}\text { SR. } \\
\text { NO. }\end{array}$ & MODE & $0-10$ & $11-20$ & $21-30$ & $31-40$ & $41-50$ & $50+$ \\
\hline 1 & RTA & $\begin{array}{c}78 \\
(10.46 \%)\end{array}$ & $\begin{array}{c}116 \\
(15.57 \%)\end{array}$ & $\begin{array}{c}242 \\
(32.48 \%)\end{array}$ & $\begin{array}{c}181 \\
(24.29 \%)\end{array}$ & $\begin{array}{c}73 \\
(9.79 \%)\end{array}$ & $\begin{array}{c}55 \\
(7.38 \%)\end{array}$ \\
\hline 2 & Fall & $\begin{array}{c}88 \\
(33.84 \%)\end{array}$ & $\begin{array}{c}67 \\
(25.76 \%)\end{array}$ & $\begin{array}{c}33 \\
(12.69 \%)\end{array}$ & $\begin{array}{c}26 \\
(10 \%)\end{array}$ & $\begin{array}{c}29 \\
(11.15 \%)\end{array}$ & $\begin{array}{c}27 \\
(10.38 \%)\end{array}$ \\
\hline 3 & Assault & $\begin{array}{c}2 \\
(1.55 \%)\end{array}$ & $\begin{array}{c}7 \\
(5.42 \%)\end{array}$ & $\begin{array}{c}46 \\
(35.65 \%)\end{array}$ & $\begin{array}{c}31 \\
(24.03 \%)\end{array}$ & $\begin{array}{c}20 \\
(15.50 \%)\end{array}$ & $\begin{array}{c}33 \\
(25.58 \%)\end{array}$ \\
\hline & TOTAL & 168 & 190 & 321 & 238 & 122 & 115 \\
\hline
\end{tabular}


Various lesions found in the head injury patients are scalp hematoma in 736(75\%) patients followed by cerebral contusions in $298(26.3 \%)$ patients and skull fractures in $170(15 \%)$ patients.

\section{Various Types of Lesions in Head Injury}

\begin{tabular}{|c|r|r|}
\hline SR. NO. & TYPE OF LESION & NO. OF PATIENTS \\
\hline 1 & SCALP HEMATOMA & $\mathbf{7 3 6}(\mathbf{7 5} \%)$ \\
\hline 2 & CEREBRAL CONTUSION & $\mathbf{2 9 8}(\mathbf{2 6 . 3} \%)$ \\
\hline 3 & SKULL FRACTURE & $\mathbf{1 7 0}(\mathbf{1 5 \%})$ \\
\hline 4 & CEREBRAL EDEMA & $\mathbf{1 5 5}(\mathbf{1 3 . 7} \%)$ \\
\hline 5 & SUBDURAL HEMATOMA & $80(\mathbf{7} \%)$ \\
\hline 6 & EXTRADURAL HEMATOMA & $62(5.5 \%)$ \\
\hline 7 & SUBARACHNOID HEMATOMA & $43(3.8 \%)$ \\
\hline 9 & INTRAVENTRICULAR HEMORRHAGE & $22(2 \%)$ \\
\hline 9 & PNEUMOCEPHALUS & $30(2.6 \%)$ \\
\hline
\end{tabular}

The distribution of lesions in various age groups is as follows:

\begin{tabular}{|l|l|l|l|l|l|l|l|}
\hline \multicolumn{7}{|c|}{ Distribution of Lesions in Various age groups } \\
\hline $\begin{array}{l}\text { SR. } \\
\text { NO. }\end{array}$ & TRAUMATIC LESION & $0-10$ & $10-20$ & $20-30$ & $30-40$ & $40+$ & TOTAL \\
\hline 1 & CEBRAL EDEMA & $22(14.2 \%)$ & $27(17.4 \%)$ & $\mathbf{4 2 ( 2 7 \% )}$ & $35(22.6 \%)$ & $29(18.7 \%)$ & 155 \\
\hline 2 & SUBDURAL HEMATOMA & $3(3.7 \%)$ & $4(5 \%)$ & $16(20 \%)$ & $21(26 \%)$ & $36(45 \%)$ & 80 \\
\hline 3 & EXTRADURAL HEMATOMA & 0 & $1(1.6 \%)$ & $11(17.7 \%)$ & $22(35.5 \%)$ & $27(43.54 \%)$ & 62 \\
\hline 4 & SUBARACHNOID HEMORRHAGE & $4(9.3 \%)$ & $2(4.6 \%)$ & $9(21 \%)$ & $10(23.3 \%)$ & $18(41.9 \%)$ & 43 \\
\hline 5 & CEREBRAL CONTUSION & $29(9.7 \%)$ & $35(11.7 \%)$ & $100(33.6 \%)$ & $54(18.1 \%)$ & $79(26.5 \%)$ & 298 \\
\hline 6 & SKULL FRACTURE & $18(10.6 \%)$ & $23(13.5 \%)$ & $\mathbf{5 7 ( 3 3 . 5 \% )}$ & $31(18.2 \%)$ & $40(23 . \% \%)$ & 170 \\
\hline 7 & INTRAVENTRICULAR HEMORRHAGE & $2(9 \%)$ & 0 & $7(31 \%)$ & $5(22.7 \%)$ & $8(36.3 \%)$ & 22 \\
\hline 8 & SCALP HEMATOMA & $\mathbf{5 8 ( 7 . 8 \% )}$ & $\mathbf{7 2 ( 9 . 7 \% )}$ & $\mathbf{2 4 8 ( 3 3 . 6 \% )}$ & $125(17 \%)$ & $233(31.6 \%)$ & 736 \\
\hline 9 & PNEUMOCEPHALUS & $2(6 \%)$ & $9(30 \%)$ & $7(23 \%)$ & 0 & $12(40 \%)$ & 30 \\
\hline 10 & DIFFUSE AXONAL INJURY & 0 & 0 & $4(50 \%)$ & $3(37.5 \%)$ & $1(12.5 \%)$ & 8 \\
\hline
\end{tabular}


Comparing various modes of Injury in conjunction with various types of Lesions shows the results as follows:

\begin{tabular}{|c|c|c|c|c|c|c|}
\hline $\begin{array}{l}\text { SR. } \\
\text { NO }\end{array}$ & $\begin{array}{l}\text { MODE OF } \\
\text { INJURY }\end{array}$ & SDH & EDH & SAH & $\begin{array}{l}\text { CEREBRAL } \\
\text { CONTUSION }\end{array}$ & $\begin{array}{c}\text { CEREBRAL } \\
\text { EDEMA }\end{array}$ \\
\hline 1 & RTA & $\begin{array}{c}72 \\
(90 \%)\end{array}$ & $\begin{array}{c}50 \\
(80.6 \%)\end{array}$ & $\begin{array}{c}29 \\
(67.4 \%)\end{array}$ & $\begin{array}{c}212 \\
(71.1 \%)\end{array}$ & $\begin{array}{c}126 \\
(81.2 \%)\end{array}$ \\
\hline 2 & FALL & $\begin{array}{c}6 \\
(7.5 \%)\end{array}$ & $\begin{array}{c}81 \\
(13 \%)\end{array}$ & $\begin{array}{c}11 \\
(25.6 \%)\end{array}$ & $\begin{array}{c}70 \\
(23.5 \%)\end{array}$ & $\begin{array}{c}21 \\
(13.5 \%)\end{array}$ \\
\hline \multirow[t]{2}{*}{3} & ASSAULT & $\begin{array}{c}2 \\
(2.5 \%)\end{array}$ & $\begin{array}{c}4 \\
(6.4 \%)\end{array}$ & $\begin{array}{c}3 \\
(7 \%)\end{array}$ & $\begin{array}{c}16 \\
(54.6 \%)\end{array}$ & $\begin{array}{c}8 \\
(5.3 \%)\end{array}$ \\
\hline & TOTAL & 80 & 62 & 43 & 298 & 155 \\
\hline
\end{tabular}

\section{Conclusion:-}

Majority of the patients admitted to the hospital with head injury was found to be males than females, with a ratio of 3:1. Among them, majority (54\%) were aged less than 30 years. Road Traffic Accident(RTA) was found to be the most common cause of head injuries with around 66\% cases mostly in the age group of 21-30 years. Around $40 \%$ of head injury patients had significant brain injury.

\section{References:-}

1. Tagliaferri F, Compagnone C, Korsic M, Servadei F, Kraus J. : A systematic review of brain injury epidemiology in Europe. Acta Neurochir (Wien). 2006;148: 255-268.

2. Chandra Shekhar, Laxmi Narayan Gupta, Ishwar Chandra Premsagar, Madhu Sinha,and Jugal Kishore : An epidemiological study of traumatic brain injury cases in a trauma centre of New Delhi (India). J Emerg Trauma Shock. 2015 Jul-Sep; 8(3): 131-139.

3. Amit Agrawal, Sagar Galwankar, Vikas Kapil, Victor Coronado, Sridhar V Basavaraju, Lisa C McGuire, Rajnish Joshi, Syed Z Quazi,Sankalp Dwivedi :Epidemiology and clinical characteristics of traumatic brain injuries in a rural setting in Maharashtra, India. 2007-2009.IJCIIS,2012,Vol.2,167-171

4. Vineet Kumar Kamal, Deepak Agrawal, Ravindra Mohan Pandey: Epidemiology, clinical characteristics and outcomes of traumatic brain injury: Evidences from integrated level 1 trauma center in India. Journal of Neuro.in rural practice, 2016 , Vol. : 7 :Issue : 4 : 515-525. 